\title{
Bacterial sepsis in neonates: Single centre study in a Neonatal intensive care unit in Bosnia and Herzegovina
}

\author{
Izeta Softić ${ }^{1}$, Husref Tahirović ${ }^{2}$, Vincenzo Di Ciommo ${ }^{3}$, Cinzia Auriti ${ }^{4}$
}

${ }^{1}$ Department of Paediatrics, University Clinical Centre Tuzla, Tuzla, Bosnia and Herzegovina, ${ }^{2}$ Department of Medical Sciences, Academy of Sciences and Arts of Bosnia and Herzegovina, Sarajevo, Bosnia and Herzegovina, ${ }^{3}$ Epidemiology Unit, Bambino Gesù Children's Hospital (IRCCS), Rome, Italy ${ }^{4}$ Department of Neonatology, Bambino Gesù, Children's Hospital (IRCCS), Rome, Italy

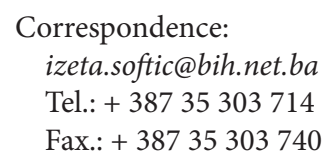

Received: 30 January 2017 Accepted: 4 May 2017

Key words: Sepsis - Neonatal intensive care unit - Antibiotics.

\begin{abstract}
Objective. The aim of the study was to evaluate the incidence, mortality, risk factors, aetiology and the susceptibility to antibiotics of the bacteria responsible for sepsis. Material and methods. A single centre, prospective, observational study, involving 200 neonates admitted over 12 months to the NICU of the University Children's Hospital, Tuzla, Bosnia and Herzegovina. Results. The crude incidence of all neonatal sepsis was $68.0 \%(136 / 200)$ and that of late-onset sepsis (LOS) was $48.5 \%$ (97/200), yelding an incidence density of LOS of 41.6/1000 patient days. LOS represented the most frequent infection and was significantly more frequent than early-onset sepsis (EOS) (71.3\% versus $28.7 \% \mathrm{p}<0.001)$. The overall mortality was $14.0 \%$, and $18.4 \%$ among infected neonates. Risk factors associated with LOS were: mechanical ventilation, intravascular catheter, surgical procedures, birth weight $\leq 1500$ g, gestational age $\leq 28$ weeks and Apgar score $\leq 3$ at 5 minutes. Culture proven sepsis developed in $43.4 \%$ of neonates. Klebsiella pneumoniae and Enterococcus faecalis were the predominant bacteria. Gram-negative bacteria were susceptible to amikacin, imipenem and meropenem; gram-positive bacteria to vancomycin and amikacin. Conclusion. Neonatal sepsis in our NICU showed a high incidence rate, and gram-negative bacteria were predominant. Low gestational age, mechanical ventilation and an intra-vascular catheter were significantly associated with sepsis. It is necessary to develop a multidisciplinary approach for routine surveillance of nosocomial infections, to improve the asepsis of therapeutic procedures, and to implement the more appropriate use of antibiotics.
\end{abstract}

\section{Introduction}

Neonatal infections currently cause about 1.6 million deaths per year in developing countries. Sepsis and meningitis are responsible for most of these deaths (1). Late-onset sepsis (LOS) is a challenging complication that affects other morbidities, length of hospitalization, cost of care, and mortality rates (2). Improvements in outcome and successful treatment depend largely on early initiation of appropriate antibiotic therapy.
The aetiology of neonatal sepsis in developing countries differs from that in developed countries in the pattern of etiological bacteria and their antibiotic susceptibility (3). In developed countries Group B Streptococcus, (GBS) is a common aetiological agent, but the burden in the developing world is less clear (4). Ampicillin and gentamicin are used as the first-line empirical treatment and the decision is traditionally based on the pathogenic flora commonly 
responsible in each neonatal unit. Antimicrobial susceptibility may vary between units and there is an increasing resistance rate of gram-negative bacteria to ampicillin, gentamicin and cefotaxime worldwide (5). Suspected bacterial infection is the main cause of neonatal admissions to hospitals in developing countries. Hospital-based studies suggest that most infections beyond the age of 72 hours are due to gram-negative pathogens, and the majority are likely to be environmentally rather than maternallyacquired. Moreover, there is a significant similarity between the causative organisms for early and late-onset sepsis in developing countries. The key pathogens are: Klebsiella species, Escherichia coli, Staphylococcus aureus and Streptococcus pyogenes (6).

Since in the literature there are no epidemiological data on neonatal sepsis and on the antibiotic susceptibility of the responsible bacteria in Bosnia and Herzegovina, this study was undertaken to describe the situation in a tertiary care hospital, providing neonatal intensive care services.

\section{Methods}

\section{Clinical setting}

The University Clinical Centre is a teaching hospital with 1373 beds, serving a population of 510,353. It is the referral centre for all inborn neonates (about 4500 deliveries annually) and for those born in the nearby hospitals, serving also for paediatric surgery when indicated. The NICU of the Department of Paediatrics provides intensive care for up to 18 patients. It has an area of $293 \mathrm{~m}^{2}$, has one common and two single isolation rooms. Visitation of mothers and visitors is limited to once per day. There is a hand washing station adjacent to the NICU, where all visitors are required to wash their hands. For all newborns, prophylactic antibiotics are routinely used (ampicillin and gentami- cin) before entering the NICU or surgery, regardless of the presence of risk factors for infections, although it is questionable.

\section{Study design and data collection}

This single centre, observational study was carried out from July 1, 2012 to June 30, 2013 and included a total of 200 critically ill hospital-born neonates, admitted to the Neonatal Intensive Care Unit (NICU) at the Children's Hospital in Tuzla, Bosnia and Herzegovina. This study had a prospective design. The study was approved by the Ethical Committee of the University Clinical Centre, Tuzla. For each enrolled neonate the demographic variables collected included: sex, birth weight (BW) and gestational age (GA). Intrauterine growth restriction was defined as birth weight for GA (BW less than $10^{\text {th }}$ percentile for GA). Other demographic data included the clinical condition of the neonates at the time of admission to the unit [the presence of major congenital malformations (7)], 5-minute Apgar score, age at admission, rectal temperature on entry; need for intubation, mechanical ventilation or exogenous surfactant, venous catheterization, lipid-containing parenteral nutrition, peripheral venous lines, continuous enteral feeding by tube, need for bladder catheterization for surgery; maternal risk factors were: fever, prolonged rupture of membrane, meconium stained-amniotic fluid, clinical signs, laboratory tests and obstetric procedures.

\section{Definitions of sepsis}

Sepsis was defined as confirmed or clinically suspected. Confirmed sepsis was defined as the presence of at least two clinical signs and/or two laboratory findings with a positive blood culture. Sepsis was defined as suspected (or clinical sepsis) when the same clinical or laboratory signs were present 
with a negative blood culture. Clinical signs of sepsis included: fever (rectal temperature $>38^{\circ} \mathrm{C}$ ), tachycardia (heart rate $>180$ beats per minute) or bradycardia (heart rate $<100$ beats per minute), apnoea lasting $>20 \mathrm{sec}-$ onds, lethargy, feeding problems, gastric billiary stasis, hemodynamic abnormalities, convulsions, and hypotonia. Laboratory signs: leucopoenia (white blood cell count $<5.000 \mathrm{~mm} 3$ ) or leucocytosis (white blood cell count $>20.000 \mathrm{~mm}^{3}$ ), low platelet count (platelets $<100.000 \mathrm{~mm}^{3}$ ), blood C-reactive protein level $>1.5 \mathrm{mg} / \mathrm{dL}$, fibrinogen $>150$ $\mathrm{mg} / \mathrm{dL}$, white blood cell immature/total ratio $\geq 0.2$, metabolic acidosis (base excess $\geq 7 \mathrm{mmol} / \mathrm{L}$ ). Sepsis acquired in the hospital that became symptomatic after hospital discharge or after the first 72 hours of life is defined as late-onset sepsis (LOS) (8). Early-onset sepsis (EOS) presented within 72 hours of life with clinical and laboratory symptoms, in the presence or absence of maternal risk factors.

\section{Microbiological analysis}

Blood culture was obtained for each neonate with signs of sepsis, by the method described by Buttery (9). The blood specimen was further inoculated into a BACTEC Peds plus/F culture vial (BACTEC, Becton Dickinson, USA) and the inoculated cultures were incubated as soon as possible in the BACTEC 9120 instrument for up to five days as recommended by Becton Dickinson Microbiological Systems (10). Sensitivity of isolated bacteria to various antibiotics was assessed by the modified Kirby and Bauer method on Mueller-Hilton agar, according to the Clinical and Laboratory Standard Institute guidelines, using an automated Vitek 2 Compact system (11).

\section{Statistical analysis}

Continuous variables were described with mean \pm standard deviation or as medians and interquartile ranges - IQR. Inferences about categorical data were analyzed using the chi-square or Fisher exact test, as appropriate. The main outcome measure of the analysis was LOS onset (suspected or confirmed) during hospitalization in the NICU, in relation to the other variables recorded. Rates of infection were calculated dividing the number of infections occurring during time of exposure by the total of exposure time. For each specific procedure the time of exposure was the time of administration of the procedure. The incidence density (ID) of infection was the ratio between the number of episodes of infection divided by the total sum of days at risk during the hospital stay (PD: person-days at risk), and the relative risk of infection associated with each variable was the ratio between the incidence rate in the risk-based group and the incidence rate in the reference group. Analyses were performed by IBM SPSS Statistics 22 and MedCalc statistical software for Windows Version 13 - 14.10.2; p values were considered statistically significant at a value of 0.05 .

\section{Results}

Two hundred infants were admitted to the NICU. Mean BW was $2915 \pm 968.74$ g; of these 200 infants, 31 were very low birth weight (VLBW). The numbers of infants in each gestational age and birth weight category are shown in Table 1.

Among the 200 neonates observed in the NICU, 136 had at least one episode of neonatal sepsis. The organisms responsible for early and late onset sepsis and their antibiotic sensitivity patterns are shown in Tables 2 and 3.

The incidence of early-onset neonatal sepsis was $28.7 \%(39 / 200)$ and the incidence of LOS was $71.3 \%$ (97/200). There were 110 episodes of LOS, yielding an incidence density of 41.6 per 1000 patient days (110/2646). Seven of 200 neonates (3.5\%) had two epi- 
Table 1 Demographic characteristics of newborns

\begin{tabular}{lllll}
\hline \multirow{2}{*}{ Demographic characteristic } & \multicolumn{3}{l}{ Newborn $(\mathrm{n}=200)$} & \multicolumn{2}{l}{$>$} \\
\cline { 2 - 5 } & \multicolumn{1}{l}{$<1500 \mathrm{~g}(\mathrm{n}=31)$} & $\mathrm{g}(\mathrm{n}=169)$ & \\
\cline { 2 - 5 } & Range & Mean \pm SD & $30-42$ & $36.74 \pm 2.75$ \\
Gestational age (Weeks) & $25-36$ & $29.71 \pm 3.24$ & $1550-4600$ & $2877.72 \pm 773.04$ \\
Birth weight $(\mathrm{g})$ & $580-1500$ & $1181.32 \pm 292.09$ & & \\
\hline
\end{tabular}

Table 2 Distribution of bacteria associated with sepsis

\begin{tabular}{ll}
\hline Pathogens & $\mathrm{n}(\%)$ \\
\hline Gram-positive bacteria & \\
\hline Enterococcus faecalis & $10(16.9)$ \\
Staphylococcus epidermidis & $7(11.9)$ \\
Staphylococcus species & $5(8.5)$ \\
Streptococcus -group B & $3(5.1)$ \\
Listeria monocitogenes & $2(3.4)$ \\
\hline Gram-negative bacteria & \\
\hline Klebsiella pneumoniae & $10(16.9)$ \\
Pseudomonas aeruginosa & $7(11.9)$ \\
Escherichia coli & $7(11.9)$ \\
Acinetobacter baumanni & $6(10.2)$ \\
Enterobacter cloacae & $2(3.4)$ \\
\hline & $59(100.0)$ \\
\hline
\end{tabular}

sodes of sepsis and 6/200 (3.0\%) had three episodes, yielding a total number of episodes of infections of 149/200 newborns. In VLBW neonates LOS was observed in 25/31 neonates, with a crude incidence of infection of $80.6 \%$ and incidence density of 52.7 (31/588), versus an incidence density of LOS in heavier neonates (>1500 grams) of $38.4(79 / 2058)$ ( $\mathrm{p}<0.25$; RR 1.37; 95\% CI 0.91-2.06).

The total number of hospital days spent in the NICU was 2646, while this number for the group of 136 infected babies was 2112 .
The mean length of hospital stay was 13.23 \pm 9.33 days for all 200 newborns. It was significantly higher in the 97 infants with LOS, than in the 64 infants that never developed sepsis, as expected $(\mathrm{p}<0.0001$, mean $18.97 \pm$ 15.49 days; median 17, IQR 5 - 27.5 days).

Mortality associated with sepsis (EOS and LOS) was $12.5 \%(25 / 200)$, accounting for $89.3 \%$ of overall neonatal mortality $(25 / 28), \mathrm{p}<0.001$. The risk of death was significantly higher among infected neonates compared to the uninfected. Twenty-five of 136 infected neonates died, yielding a crude mortality rate of $18.3 \%$ versus $4.6 \%$ among uninfected neonates, $(\mathrm{p}<0.02$, RR $3.92,95 \%$ CI 2.89-10.28) and also compared to the mortality observed in the entire group of neonates enrolled $(\mathrm{p}<0.03 ; \mathrm{RR} 1.31 ; 95 \%$ CI 0.80-2.15). The risk of death was significantly higher in the VLBW infected infants compared to the others (48\% versus $12.2 \%$, RR: 3.40; 95\% CI 1.71-6.64; $\mathrm{p}<0.004)$.

The incidence density of sepsis in NICU by selected clinical characteristics and invasive procedures is shown in Table 4 . VLBW, extreme prematurity ( $<28$ gestational age), 5 -minute Apgar score $\leq 3$, assisted ventilation, the presence of a central venous catheter and surgical intervention were all significantly associated with a higher incidence of LOS sepsis 
Table 3 Antibiotic susceptibility for of Gram-negative and Gram-positive bacteria isolated from blood cultures

\begin{tabular}{|c|c|c|c|c|c|}
\hline \multirow{3}{*}{ Antibiotics } & \multicolumn{5}{|c|}{ Gram-negative bacteria $(n=32)$} \\
\hline & $\begin{array}{l}\text { Klebsiella pneumoniae } \\
(\mathrm{n}=10)\end{array}$ & $\begin{array}{l}\text { Escherichia coli } \\
(\mathrm{n}=7)\end{array}$ & $\begin{array}{l}\text { Enterobacter } \\
\text { cloace }(\mathrm{n}=2)\end{array}$ & $\begin{array}{l}\text { Pseudomonas } \\
\text { aeruginosa }(n=7)\end{array}$ & $\begin{array}{l}\text { Acinetobacter } \\
\text { baumanni }(n=6)\end{array}$ \\
\hline & $\mathrm{n}(\%)$ & $\mathrm{n}(\%)$ & n (\%) & $\mathrm{n}(\%)$ & n (\%) \\
\hline Ampicillin & $\mathrm{R}$ & $\mathrm{R}$ & $\mathrm{R}$ & $\mathrm{R}$ & $\mathrm{R}$ \\
\hline AMC & $1(10)$ & $\mathrm{R}$ & $\mathrm{R}$ & $\mathrm{R}$ & $\mathrm{R}$ \\
\hline Ceftriaxone & $4(40)$ & $6(85.7)$ & $1(50)$ & $5(71.4)$ & $\mathrm{R}$ \\
\hline Cefotaxime & $4(40)$ & $3(42.8)$ & $1(50)$ & $4(57.1)$ & $\mathrm{R}$ \\
\hline Ceftazidime & $4(40)$ & $6(85.7)$ & $1(50)$ & $5(71.4)$ & $\mathrm{R}$ \\
\hline Cefepime & $4(40)$ & $7(100)$ & $1(50)$ & $5(71.4)$ & $\mathrm{R}$ \\
\hline Imipenem & $10(100)$ & $6(85.7)$ & $2(100)$ & $6(85.7)$ & $\mathrm{R}$ \\
\hline Meropenem & $10(100)$ & $27(100)$ & $2(100)$ & $6(85.7)$ & $\mathrm{R}$ \\
\hline Amikacin & $10(100)$ & $4(57.1)$ & $1(50.0)$ & $7(100)$ & $\mathrm{R}$ \\
\hline Gentamicin & $2(20)$ & $3(42.8)$ & $1(50.0)$ & $7(100)$ & $\mathrm{R}$ \\
\hline Tobramycin & $10(100)$ & $7(100)$ & $2(100)$ & $7(100)$ & $6(100)$ \\
\hline Ciprofloxacin & $1(10)$ & $4(57.1)$ & $1(50.0)$ & $5(71.4)$ & - \\
\hline Tigecycline & $10(100)$ & NT & $1(50.0)$ & $7(100)$ & $6(100)$ \\
\hline \multirow[t]{2}{*}{ TMP/SMX } & $5(50)$ & $\mathrm{R}$ & $1(50.0)$ & $\mathrm{R}$ & $\mathrm{R}$ \\
\hline & \multicolumn{5}{|c|}{ Gram-positive bacteria $(n=27)$} \\
\hline \multirow[t]{2}{*}{ Antibiotics } & $\begin{array}{l}\text { Staphylococcus } \\
\text { epidermidis } \\
(\mathrm{n}=7)\end{array}$ & $\begin{array}{l}\text { Enterococcus } \\
\text { faecalis } \\
(n=10)\end{array}$ & $\begin{array}{l}\text { Streptococcus } \\
\text { Spp. } \\
(n=5)\end{array}$ & $\begin{array}{l}\text { Streptococcus } \\
\text { agalactiae } \\
(n=3)\end{array}$ & $\begin{array}{l}\text { Listeria } \\
\text { monocitogenes } \\
(\mathrm{n}=2)\end{array}$ \\
\hline & $n(\%)$ & $\mathrm{n}(\%)$ & n (\%) & n (\%) & $\mathrm{n}(\%)$ \\
\hline Ampicillin & NT & $2(20)$ & $1(20)$ & $3(100)$ & $2(100)$ \\
\hline Penicillin & $\mathrm{R}$ & $\mathrm{R}$ & $2(40)$ & $1(33.3)$ & $2(100)$ \\
\hline Oxacillin & $\mathrm{R}$ & NT & $\mathrm{R}$ & NT & NT \\
\hline Ciprofloxacin & $3(42.8)$ & NT & NT & NT & NT \\
\hline Gentamicin & $2(28.5)$ & $3(30)^{*}$ & $5(100)$ & $3(100)$ & $2(100)$ \\
\hline Amikacin & $7(100)$ & $10(100)$ & $5(100)$ & NT & NT \\
\hline TMP/SMX & $2(28.5)$ & NT & $1(20)$ & $1(33.3)$ & $2(100)$ \\
\hline Clindamycin & $6(85.7)$ & $1(10)$ & $1(20)$ & $3(100)$ & NT \\
\hline Rifampin & $6(85.7)$ & NT & $5(100)$ & $3(100)$ & NT \\
\hline Vancomycin & $7(100)$ & $10(100)$ & $5(100)$ & $3(100)$ & NT \\
\hline
\end{tabular}

NT=not tested for susceptibility; R=Resistance; AMC=Amoxicillin/Clavulanic Acid; TMP/SMX=Trimethoprim/Sulfamethoxazole; *Gentamicin disk $120 \mathrm{mg}$. 
Table 4: Incidence density of sepsis in NICU by selected clinical characteristics and invasive procedures

\begin{tabular}{|c|c|c|c|c|}
\hline Characteristics & No. of patients & $\mathrm{ID}^{+}$ & $\mathrm{RR}^{\ddagger}$ & $95 \% \mathrm{Cl}$ \\
\hline \multicolumn{5}{|l|}{ Birth weight (g) } \\
\hline$\leq 1500$ & 31 & 52.7 & 1.37 & \multirow{2}{*}{$0.91-2.06$} \\
\hline$>1500$ & 169 & 38.4 & 1 & \\
\hline \multicolumn{5}{|c|}{ Gestational age ${ }^{\S}$} \\
\hline$<28$ & 8 & 85.1 & 2.29 & $0.81-5.81$ \\
\hline $28-31$ & 25 & 39.0 & 1 & $0.59-1.70$ \\
\hline$>31-36$ & 84 & 43.5 & 1.12 & \multirow{2}{*}{$0.73-1.68$} \\
\hline$\geq 37$ & 83 & 39.1 & 1 & \\
\hline \multicolumn{5}{|l|}{ Gender } \\
\hline Male & 115 & 41.8 & 1.02 & \multirow{2}{*}{$0.70-1.47$} \\
\hline Female & 85 & 41.2 & 1 & \\
\hline \multicolumn{5}{|l|}{ MCM\| } \\
\hline Present & 14 & 48.2 & 1.18 & \multirow{2}{*}{$0.64-2.16$} \\
\hline Absent & 186 & 40.9 & 1 & \\
\hline \multicolumn{5}{|l|}{ Apgar score" } \\
\hline$\leq 3$ & 7 & 98.0 & 2.45 & \multirow[t]{2}{*}{$1.04-5.76$} \\
\hline $4-6$ & 17 & 44.4 & 1.11 & \\
\hline $7-10$ & 176 & 40.1 & 1 & $0.60-2.04$ \\
\hline \multicolumn{5}{|c|}{ Assisted ventilation ${ }^{\dagger+}$} \\
\hline With & 67 & 196.4 & 4.36 & \multirow{2}{*}{$3.05-6.23$} \\
\hline None & 133 & 45.0 & 1 & \\
\hline \multicolumn{5}{|l|}{$\mathrm{CVC}^{\ddagger \neq}$} \\
\hline With & 84 & 95.9 & 3.44 & \multirow{2}{*}{$2.39-4.93$} \\
\hline None & 116 & 27.9 & 1 & \\
\hline \multicolumn{5}{|c|}{ Surgical intervention } \\
\hline With & 9 & 80.3 & 2.03 & \multirow{2}{*}{$1.12-3.70$} \\
\hline None & 191 & 39.5 & 1 & \\
\hline & Total & 41.6 & - & - \\
\hline
\end{tabular}

${ }^{+}$Incidence density (the ratio between the number of episodes of infection divided by the sum of days at risk during the hospital stay); "Relative risk (ID1/ID0); §Weeks; " Major congenital malformations; ' $A t 5$ minutes; ${ }^{\dagger+}$ Continuous Positive Airway Pressure-Orotracheal tube; ${ }^{{ }^{\ddagger} C}$ Central venous catheter.

\section{Discussion}

To our knowledge, this is the first prospective observational study that describes the rate, aetiology and some of the risk factors of neonatal sepsis in an NICU in Bosnia and Herzegovina. The sudy by Hadzimuratovic et al. was limited to premature infants with congenital heart disease, and found a higher risk of acquiring sepsis during hospitalization in an NICU (12).

The high incidence and overall mortality rate from sepsis, especially among VLBW infants, and the high incidence density of LOS are in line with investigations from developing countries (13-15). The most common causes of death in the neonatal period in developing countries are infections (1). 
Timely microbiological surveillance and assessment of antimicrobial resistance is a key component in decreasing the rate of neonatal sepsis and the associated mortality. There are a number of important gaps in our knowledge and a lack of studies looking at simple and sustainable interventions to reduce the burden of neonatal sepsis. The lack of culture driven antimicrobial therapy and limited consistent infection control practices are likely responsible for the high incidence rates of neonatal sepsis and mortality.

There are no comprehensive studies available in developing counties, because no National Nosocomial Infection Surveillance Systems (NNISS), which develop surveillance and preventive strategies to break down nosocomial infections, have been implemented. To implement such NNISS could be critical in abating this clinical and public health problem.

There is a general lack of precision in defining sepsis in developing countries. Micribiological results in many developing countries may require several days to become positive. Moreover, in neonates the incidence of positive blood cultures in the course of sepsis often does not reach 50\% of samples (16). In our unit, rates of resistance for gram-negative and gram-positive bacteria were high, leading to a great deal of concern with respect to infection control and antibiotic prescribing practices. Gramnegative bacterias were more frequently isolated, which is a common finding from countries with low resources, overcrowding and poor staffing patterns in hospitals $(17,18)$. They were even highly resistant to ampicillin and gentamicin. In our unit there has been a questionable routine practice to start antibiotics for all new-borns regardless of clinical signs. Cephalosporins and an aminoglicoside (amikacin) have been the first line therapy because of the high resis- tance to recommended empirical therapy with ampicillin and gentamycin. A preponderance of enterobacteria has been noted in other similar clinical settings $(19,20)$. This problem might be prevented through limitation of the use of the latest generation of cephalosporin, and specific prevention measures, such as hand washing. The current standard practice of unselective use of antibiotic therapy for every new-born entering the NICU is one that needs revision.

Low birth weight and prematurity increase the risk of neonatal sepsis, but in our study it did not reach statistical significance. In other studies, $20 \%$ of VLBW preterm infants experienced a serious systemic infection. Furthermore, the mortality rate was as much as threefold higher than their counterparts without sepsis during their hospitalization (21). In this study, the overall mortality rate associated with sepsis was high for the entire group of infected babies. In the group of VLBW the incidence was twofold higher. However, there were only 31 VLBW neonates in our population.

Among the biological characteristics, extreme prematurity ( $<28$ gestational age), and 5-minute Apgar score $\leq 3$ were risk factors for LOS among our patients, confirming the data from major literature on this topic (22). Among the therapeutic procedures associated with LOS, assisted ventilation, the presence of a central venous catheter and surgical intervention markedly increased the risk of infection. Moreover, invasive procedures in association with prematurity are risk factors for acquiring sepsis, especially in settings with a high intensity of colonization pressure, which is characteristic for developing countries $(23,24)$. The current standard practice of unselective use of antibiotic therapy for every new-born entering the NICU may be a limitation and it needs to be modified. 


\section{Conclusion}

A high incidence and mortality rate from sepsis especially in VLBW infants, a high incidence density of LOS, a low rate of positive blood culture and a higher frequency of isolated, very resistant gram-negative bacteria are presented in this study. The paucity of data in the medical literature on neonatal sepsis in Bosnia and Herzegovina is a matter of concern for all those who work with neonates, especially in NICUs. Another aspect that must be addressed is the rational use of antibiotics. Specific guidelines for prescribing antibiotic therapy and applying invasive procedures for neonates in NICUs are important means to limit the development of resistant pathogens. Understanding the aetiology and epidemiology of neonatal sepsis and their changes over time is a key component in the reduction of sepsis and mortality of neonates in Bosnia and Herzegovina. Only a multidisciplinary approach, with contributions from neonatologists, infection control practitioners and microbiologists, will reduce the incidence of neonatal sepsis. Limited-resource countries need to reach the quality of health care and patient safety that we find in developed countries.

\footnotetext{
What is already known on this topic

Neonatal bacterial sepsis continues to be major cause of morbidity and mortality in the developing world. Differences in epidemiology between developed and developing countries have been identified.
}

What this study adds

Our results from an observational study suggest the nosocomial origin of neonatal bacterial sepsis caused by predominant gram-negative bacteria. Early and focused treatment with optimal antibiotic therapy is essential for better management of neonatal bacterial sepsis in our hospital.

Authors' contributions: Conception and design: IS and HT; Acquisition, analysis and interpretation of data: IS and CA; Drafting the article: IS, CA and HT; Revising it critically for important intellectual content: HT and CA; Approved final version of the manuscript: IS, HT, CA and VC.
Conflict of interest: The authors declare that they have no conflict of interest.

\section{References}

1. Vergnano S, Sharland M, Kazembe P, Mwansambo C, Heath PT. Neonatal sepsis: an international perspective. Arch Dis Child Fetal Neonatal Ed. 2005;90(3):F220-4.

2. Kristóf K, Kocsis E, Nagy K. Clinical microbiology of early-onset and late-onset neonatal sepsis, particularly among preterm babies. Acta Microbiol Immunol Hung. 2009;56(1):21-51.

3. Daoud AS, Abuekteish F, Obeidat A, el-Nassir Z, al-Rimawi $H$. The changing face of neonatal septicaemia. Ann Trop Pediatr. 1995;15(1):93-6.

4. Dangew AF, Cunnington MC, Dube Q, Edwards MS, French N, Heyderman RS et al. Variation in reported neonatal group B streptococcal disease incidence in developing counties. Clin Infect Dis. 2012;55(1):91-102.

5. Bradford PA. Extended specrum beta lactamases in the 21st century: Characterisation epidemiology and detection of this important resistance threat. Clin Microbiol Rev. 2001;14(4):933-51.

6. Zaidi AK, Thaver D, Ali SA, Khan TA. Pathogens associated with sepsis in newborns and young infants in developing countries. Pediatr Infect Dis J. 2009;28(1 Suppl):S10-8.

7. Smith DW. Recognisable paterns of human malformation. Genetic, embriologic and clinical aspects. Third edition. Major Probl Clin Pediatr. 1982;7:1-653.

8. Garner JS, Jarwis WR, Emori TG, Horan TC, Hughes JM. CDC definition for nosocomial infection. Am J Infect Control. 1988;16(3):128-40.

9. Buttery JP. Blood cultures in newborns and children: Optimizing an everyday test. Arch Dis Child Fetal Neonatal Ed. 2002;87(1):F25-8.

10. Becton Dickinson Microbiological Systems. BACTEC PEDS PLUS/F culture vials: Instruction leaflet. Sparks, Mariland: Becton Dickinson Company; 2000.

11. National Committee for Clinical Laboratory Standards. Performance standards for antimicrobial susceptibility testing. NCCLS approved standard M 100-S9. Wayane, PA: National Comittee for Clinical Laboratory Standards; 1999.

12. Hadzimuratovic E, Dinarevic SM, Hadzimuratovic A. Sepsis in premature newborns with congenital heart disease. Congenit Heart Dis. 2010;5(5):435-8.

13. Macharashvili N, Kourbatova E, Butsoshvili M, Tsertshvadze T, McNutt LA, Leonard MK. Eti- 
ology of neonatal blood stream infections in Tbilisi, Republic of Georgia. Int J Infect Dis. 2009;13(4):499-505.

14. Al-Shamaly HA, Sabrah AA, Al-Robasi AB, Naser SM. Types of bacteria associated with neonatal sepsis in Al-Thavara University Hospital, Sana, Yemen, and their antimicrobial profile. Sultan Qaboos Univ Med J. 2012;12(1):48-54.

15. Kuruvilla KA, Pillai S, Jesudason M, Jana AK. Bacterial profile of sepsis in neonatal unit in south India. Indian Pediatr. 1998;35(9):851-8.

16. Vamsi SR, Bhat RY, Lewis LE, Vandana KE. Time to positivity of blood cultures in neonates. Pediatr Infect Dis J. 2014;33(2):212-4.

17. Viswanathan R, Singk AK, Ghosh C, Dasgupta S, Mukherjee S, Basu S. Profile of neonatal septicaemia et district-level sick newborn care unit. J Health Popul Nutr. 2012;30(1):41-8.

18. Softić I, Tahirović H, Skokić F, Tihić N, Di Ciommo V, Auriti C. An outbreak of nosocomial infection with acinetobacter baumannii in neonatal intensive care unit of the Departement of pediatrics, University clinical centre Tuzla, Bosnia and Herzegovina. Paediatrics Today. 2013;9(2):163-9.
19. Bas AY, Demirel N, Zenciroglu A, Gol N, Tanir G. Nososcomial bloodstream infections in a neonatal intensive care unitin Ancara, Turkey. Turk J Pediatr. 2010;52(5):464-70.

20. Kaufman D, Fairchild KD. Clinical microbiology of bacterial and fungal sepsis in very-low-birthweight infants. Clin Microbiol. 2004;17(3):638-80.

21. Hwang JH, Choi CW, Chang YS, Choe YH, Park WS, Shin SM, et al. The efficacy of clinical strategies to reduce nosocomial sepsis in extremely low birth weight infants. J Korean Med Sci. 2005;20(2):177-81.

22. Narayan S, Aggarwal R, Upadhyay A, Deorari AK, Singh M, Paul VK. Survival and morbidity in extremely low birth weight (ELBW) infants. Indian Pediatr. 2003;40(2):130-5.

23. Litzow JM, Gill CJ, Mantaring JB, Fox MP, MacLeod WB, Mendoza M. High frequency of multidrug-resistent gram-negative rods in 2 neonatal intensive care units in the Philippins. Infect Control Hosp Epidemiol. 2009;30(6):543-9.

24. Sankar MJ, Agarwal R, Deorari AK, Paul VK. Sepsis in the newborn. Indian J Pediatr. 2008;75(3):261-6. 